This is the author's version of the work

It is posted here by permission of Australian Academic Press for personal use, not for redistribution. The definitive version was published as:

Bruyère, S. (2006). Disability management: Key concepts and techniques for an aging workforce. International Journal of Disability Management Research, 1, 149-158. http://dx.doi.org/ 10.1375/jdmr.1.1.149

\title{
Disability Management: Key Concepts and Techniques for an Aging Workforce ${ }^{1}$
}

By

\author{
Susanne M. Bruyère, Ph.D., CRC ${ }^{2}$ \\ Cornell University \\ Employment and Disability Institute \\ School of Industrial and labor Relations \\ Ithaca, New York 14853-3901, U.S.A.
}

\author{
Prepared for \\ Third International Forum on Disability Management \\ October 7, 2006 \\ Brisbane, Australia
}

\footnotetext{
${ }^{1}$ This research was funded by three grants to Cornell University from the U.S. Department of Education, National Institute on Disability and Rehabilitation Research (NIDRR): Grant No. H133A70005 (Improving Employer Practices Covered by Title I of the ADA), Grant No. H133B980038 (Rehabilitation Research and Training Center on Economic Research on Employment Policy for People with Disabilities), and Grant No. H133G040265 (Using the U.S.EEOC Employment Discrimination Charge Data System for Research and Dissemination Purposes).

${ }^{2}$ The author would like to acknowledge the Employment and Disability Institute's William Erickson, Research Specialist, for figure preparation, and Sara VanLooy, Administrative Research Assistant, for her contribution in the background research and editing of this paper.
} 


\begin{abstract}
The aging workforce is likely to result in increasing numbers of workers with disabilities. The U.S. Census Bureau projects that the 45-54 and 55-64 year-old population in the United States will grow by nearly 44.2 million (17\%) and 35 million (39\%) in the next ten years (U.S. Census Bureau, 2004). By the year 2010, this group will account for nearly half (44\%) of the working age population (20-64), and the number of people with disabilities between the ages of 50 and 65 will almost double (Weathers, 2006). Disability management and accommodation policies and practices readily lend themselves to addressing the challenges employers will face with an aging workforce, and the increasing prevalence of disability which these demographics bring. Proactive education about ways to maximize the productivity of an aging workforce, effective case management, and workplace accommodation can significantly contribute to maximizing aging worker retention.
\end{abstract}




\section{Introduction}

For nearly three decades, disability management has focused on effective retention of workers who incur illness or injury that affects their attachment to the workforce. The purpose of this paper is to encourage exploration of the application of disability management to the pressing issues created globally by the aging population. With the workforce shrinking in many parts of the world, older workers will become valuable members of the job pool. Years of experience in the application of disability management can contribute to the retention of aging workers who will likely need similar intervention and workplace supports.

In this article, we offer a selection of literature documenting the extent of the aging workforce issue and the challenges it may create, to spark discussion from the perspectives of workforce planning, workplace policies and practices, the employment and retirement choices of aging workers, and unique considerations for workers with disabilities. Our focus is the implications for disability management practice, policy, and research.

\section{Issues of an Aging Workforce}

Figure 1 shows the projected change in the 55-64 year-old age group between the years 2000 and 2015 for a selection of countries. The range of changes globally is very wide -- from a $-4 \%$ change rate in Zimbabwe, to a $+182 \%$ for Singapore. Although projections differ between and among developed and less developed countries, there is no doubt that in general the aging cohort will increase, with a profound effect on the distribution of the global work force in the decades to come (Bourgault, Lawrence, \& Steiniger, 2004). 
In the U.S., older workers are one of the fastest growing segments of the workforce. The U.S. Bureau of Labor Statistics estimates that between the years 20022012, the number of workers 55 years and older will grow by 50\% (Reynolds, Ridley, \& Van Horn, 2005).

Aging Workforce - Problem or Panacea?

Not everyone agrees on the implications of a large group of older workers in the workforce. Some employers express concern about a possible labor shortage (Collison, 2005), and many see a lack of competencies in the younger workers who will replace them (Collison, 2006). As the seasoned workforce ages and retires, taking with them critical knowledge, businesses face a shortage of labor and loss of institutional memory and productivity, especially in specific skill areas, particularly in industrialized countries (Frank \& Taylor, 2004; Ghosheh, Lee, \& McCann, 2006).

Others feel that the workforce challenge of the future is not a labor shortage but an oversupply of older workers. Changes in the global economy may push older workers to work longer to fund their retirements (Helman, Copeland, \& VanDerhei, 2006).

Nearly a quarter of U.S. workers surveyed in 2005 said that they would be working either full or part time for needed income following retirement, compared to only $13 \%$ five years earlier (Reynolds, Ridley, \& Van Horn, 2005). Some employers see employees choosing to stay on the job longer than they have in the past, and are concerned about conflicting information on the costs of employing older workers (Brooke, 2003; Card \& O’Donnell, 2004).

Increased Disability In the Aging Workforce 
A number of studies examine the impact of aging on the occurrence of disability. Research shows that the incidence and prevalence of disability increases with age (He, Sengupta, Velkoff, \& DeBarros, 2005). Some say that as workers age they have more difficulty performing physical tasks and are more susceptible to injury (Canadian Centre for Occupational Health and Safety, 2002; Minter, 2002).

A U.S. study using state data on workers' compensation claims suggested that while older workers have fewer workplace accidents, they are more likely to have permanent disabilities as a result of work-related injuries (Biddle, Boden, \& Reville, 2003).

Ho (2002) used the 1996 Survey of Income and program Participation (SIPP) to show that the chance of becoming disabled increases substantially with age, from 3.1\% for adults younger than 45 years old to $18.5 \%$ for those aged 55 to 64 . Platt (2001) found that by the age of 50 a person's first serious medical problem will occur, with a $25 \%$ chance that it will be a life-long condition. Platt also emphasizes the importance of return-to work initiatives for baby boomers, predicting that without this the cost of shortand long-term disability as well as workers' compensation will escalate.

\section{Discriminatory Workplace Environment}

The culture of the workplace itself is a significant factor influencing the retention or rejection of older workers. Age-based stereotyping perpetuates discriminatory practices and discourages older workers from remaining in or returning to the workplace.

Until recently, age has been viewed as an appropriate measure of disability. It was assumed that all workers over a specific chronological age would not be able to perform normally. Aging persons were viewed as disabled by definition. 
Research suggests that employers discriminate against older workers in the application process (Bendick, Brown, \& Wall, 1999; Lahey, 2005). Younger workers’ beliefs about aging greatly influence workplace dynamics (Card \& O’Donnell, 2004). Stereotypes of older workers (e.g. inflexible, sicker, and unwilling to learn new technology) appear to be dissipating, but persist at many levels. Such stereotypes have clearly had an influence on older workers' (particularly men’s) labor force participation rates (Schultz, Sirotnik, \& Bockman, 2000).

Workers who experience age discrimination are more likely to leave their current employment and less likely to remain employed (Johnson \& Neumark, 1996). In addition, a non-receptive and non-accommodating environment may lead to claims of discrimination. Age discrimination claims are the fastest growing category of discrimination cases filed with the U.S. Equal Employment Opportunity Commission (EEOC) (Williams, 2002). They are making up a larger percentage of all charges filed (Morton, Foster, \& Sedlar, 2005). Between 1992 and 2003, the top issues involved in ADEA claims were discharge, hiring, and layoff. More claims of discrimination in hiring were filed under the ADEA than the ADA in that time (19,561 vs. 12, 379). ${ }^{3}$

\section{Effective Aging Workforce Retention Strategies}

Incentives and workplace supports will be needed to encourage employers to retain older workers and to encourage older workers to remain in the workforce (Laws, 2006). Keeping senior workers preserves invaluable knowledge and creates beneficial workplace diversity (Card \& O’Donnell, 2004). Here we provide strategies from the

\footnotetext{
${ }^{3}$ Source: Cornell University EEOC Charge Data Study; ADA and ADEA EEOC charges by issue, 19922003. (2005). Unpublished report. Ithaca, NY: Cornell University, ILR School, Employment and disability Institute. S. Bruyère, Principal Investigator; A. Ruiz-Quintanilla, Co-PI; A. Houtenville and S. Schwab, Consultants.
} 
literature to address the issues of an aging workforce, including workforce development, changes in workplace policies and practices, and creating a culture of inclusion and accommodation.

Workforce Development

Experienced workers have distinct performance advantages, particularly in roles that require advanced skills, training, experience, and company-specific knowledge (AARP, 2005). The cost of replacing experienced workers is often significant. Some businesses are offering workers training and educational opportunities in an attempt to address the anticipated skill shortage and shrinking labor pool (Collison, 2006).

The success of such initiatives can be significantly increased through state funded initiatives and government agency support for partnerships dedicated to training or upgrading the labor force (Turning boomers into boomerangs, 2006). These would also offer incentives to educational institutions for providing programs that help employees upgrade job skills. State or local governments could also assist by offering incentives to employees for upgrading job skills and to employers who provide such opportunities (Shultz, Sirotnik, \& Bockman, 2000).

Training is an important component of retention. However, employers have been slow to provide training for older employees, and some key needs (access to training; recognition of the different learning styles of older employees; and manager awareness training) are not always met (Armstrong-Stassen \& Templar, 2005). Certain training approaches can provoke anxiety in older workers (Delgoulet \& Marquie, 2002). Focus groups of older workers should test training approaches being targeted to older workers, to minimize anxiety and maximize effectiveness. 
Most workers today must interact with computers simply to perform their jobs.

This need for adaptations of information systems to increase usability for older workers has implications for designers (Czaja \& Hiltz, 2005).

Workplace Policies and Practices

Changes in a variety of HR and management practices can aid retention of older workers. Companies are recognizing that a mature workforce can increase customer satisfaction and profitability, but effective intergenerational inclusion initiatives are required (Morton, Foster, \& Sedlar, 2005, p. 5). Company policies and practices should include alternatives, such as flex-place and flex-time agreements, that will reflect older workers' desire for flexible working hours, part-time positions, and the ability to choose what part of the work day they work. Telecommuting technology has made offering these options more viable (Card \& O’Donnell, 2004).

Other approaches include: communicating with an intergenerational approach, building a retiree network, offering benefits tailored to mature employees (such as longterm care insurance, pre-retirement planning, health and wellness programs, and comprehensive medical coverage), and prorating benefits for flex-time employees (The Institute of Management and Administration, 2005).

Benefit plans may create an impetus for older workers to retire (Kramer, 1995). Some employers are creating health care and retirement policies that offer incentives to older workers to stay engaged in the workforce (e.g. phased retirement, "in demand" consulting workforce, using senior staff for mentoring new workers, casual/part-time workers programs; and discounts on pharmaceuticals and health screenings) (Morton, Foster, \& Sedlar, 2005). 


\section{Minimizing Age Discrimination through Workplace Culture and Accommodations}

A Cornell University survey of HR professionals (Bruyère, 2000) found that when a disability management program was in place, it raised supervisor awareness of accommodations, created an organizational structure for accommodations, and raised acceptance of employees with disabilities. All these things can contribute positively to a workplace culture that succeeds in retaining older workers. Organizations with cultures of trust and inclusion allow for open dialogue, permitting them to plan and control outcomes. Successful companies make it a priority to create a workplace culture that embraces and encourages diversity. There needs to be a greater movement toward eliminating age-based discrimination in the workplace (Bourgault, Lawrence, \& Steiniger, 2004).

Although age discrimination laws protect older workers, some are not covered by them and may be better protected by disability discrimination laws (Hotchkiss, 2003; Stock \& Beegle, 2004). U.S. EEOC claims data show that a significant number of discrimination charges are jointly filed under both the ADA and ADEA - 34.4\% of charges for cardiovascular disability, $19.2 \%$ of relationship/association charges, $17.7 \%$ of diabetes charges, and $16.4 \%$ of "regarded as disabled" charges were filed jointly. ${ }^{4}$ Understanding the interplay between aging and disability is crucial to effectively minimize discrimination claims.

What was considered a general disability called "old age" is in fact a variety of disabilities that can be associated with aging to various degrees. A specific impairment

\footnotetext{
${ }^{4}$ Source: Cornell University EEOC Charge Data Study; ADA and ADEA EEOC charges by issue, 19922003. (2005). Unpublished report. Ithaca, NY: Cornell University, ILR School, Employment and disability Institute. S. Bruyère, Principal Investigator; A. Ruiz-Quintanilla, Co-PI; A. Houtenville and S. Schwab, Consultants.
} 
can often be accommodated with ergonomic redesign or new training. (Tepas \& BarnesFerrell, 2002).

As the average age of the workforce increases, the incidence, severity, and duration of disability is also likely to increase. It will become even more important to identify proven strategies to return employees to productive roles (Vargo \& Grzanowicz, 2002). This is relevant not only in the U.S., but also in the European Union, where agerelated adjustments of physical requirements in the workplace are being demanded (Ilmarinen, 2002).

Smith (2004) discusses particular challenges for safety professionals posed by older workers. He cites Donald Wright, director of OSHA’s Office of Occupational Medicine, who says that older workers "often suffer from a loss of visual acuity, hearing loss, decreased coordination and balance, and medical conditions that put them at greater risk of suffering workplace injuries” (p. 28).

Age-related changes in physical and cognitive abilities can raise challenges for older adults, but with optimal person-environment-fit many can continue to work safely and successfully (Hansson, Robson, \& Limas, 2001). Research conducted by Burkhauser, Butler, and Weathers (2001) suggests that workers who were accommodated following the onset of a disability were significantly less likely to apply for SSDI benefits within three years. If the work environment is supportive, and accommodations are provided, the likelihood of a worker with a disability leaving the workplace is considerably decreased.

Several studies highlight the importance of workplace accommodation for older workers. Data from the U.S. National Health Interview Survey Disability Supplement 
shows that older workers were more likely than others to receive accommodations (Zweling, Whitten, Spring, Davis, Wallace, Blanck, \& Heeringa, 2003).

There is room for improvement, and encouragement for accommodation by employers is needed. Yelin, Sonneborn, and Trupin (2000) found that overall less than one in five persons aged 51-61 with musculoskeletal conditions who had a disability indicated that they had received any form of accommodation in their current jobs.

U.S. Census 2000 data showed $16 \%$ of older men and $13 \%$ of older women had a sensory disability (He, et al., 2005). Bruyère (2000) reports that employers were least familiar with accommodations for visual and hearing impairments, found such accommodations more difficult to make, and had made accommodations for these disabilities much less frequently than for other types. Since loss of visual and hearing acuity is more common in older workers, this lack of experience suggests employers are unprepared to accommodate these disabilities.

In a follow-up survey of HR practitioners on information technology accessibility, the majority of organizations reported using Web processes for job postings, benefits self service, and employee training (Bruyère, Erickson, \& VanLooy, 2005). The majority of employees used computers more than half the workday. Nearly half the respondents reported having made some type of adaptation to make a computer accessible to an employee with a disability.

Another area in need of attention is the impact of the aging process on workers with disabilities. Mitchell, Adkins, and Kempt (2006) investigated the role of both aging and disability on employment status over the life span. Data from the disability group showed a faster and earlier decline in employment over the life span than the comparison 
group. The disability group reported a $50 \%$ reduction in employment by their $60 \mathrm{~s}$, compared to $35 \%$ for the control group.

\section{Implications for Disability Management Practice, Policy, and Research}

The primary emphasis of disability management in the employment setting is preventing or minimizing the impact of the disability on the employer and employee and assisting in job retention. In this context disability management represents a comprehensive set of skills and services (including case management) which are necessary to effectively address the healthcare planning and resource management needs of an aging population (Doyle, Dixon, \& Moore, 2003).

Practitioners, program administrators, and researchers are being offered a new opportunity. Disability management specialists, many of whom have rehabilitation and mental health consulting backgrounds, can assist employers in assessing the needs of their aging work force and developing training programs to help retain older workers (Dixon, Richard, \& Rollins, 2003). To be able to confront myths and dispel stereotypes, they will need knowledge of the intellectual, social, and emotional well-being of older adults (American Psychological Association, 1998).

Rehabilitation counselors and disability management professionals should be knowledgeable about employment nondiscrimination legislation (Finch \& Robinson, 2003). These professionals also need to be aware of the possible attendant mental health considerations in the aging process (Swett \& Bishop, 2003), and must also keep in view the aging of people with existing disabilities (Larkin, Alston, Middleton, \& Wilson 2003). The increasingly IT-intensive work environment requires knowledge of specific usability concerns and technology adaptations to ensure effective functioning. 
Research is needed on the issues of aging workers, such as training needs, career transition issues, and retirement planning (Shultz, Sirotnik, \& Bockman, 2000). Research can also demonstrate which accommodations, workplace modifications, and policy and practice changes may positively impact the retention and productivity of an aging workforce. Disability management researchers are in a unique position to provide the design conceptualization, metrics, and analyses to test the wealth of interventions we will be exploring to keep our aging workforce healthy and fully engaged in the employment environment. Disability practitioners will be needed to implement these interventions. A focus globally on these issues by the disability management field is imperative. 


\section{References}

AARP (2005). The business case for workers Age 50+: Planning for tomorrow's talent needs in today's competitive environment. Washington, D.C.: Author.

American Psychological Association (1998). What practitioners should know about working with older adults. Professional Psychology: Research and Practice, 29(5), 413427.

Armstrong-Stassen, M., and Templar, A. (2005). Adapting training for older employees: The Canadian response to an aging workforce. The Journal of Management Development, 24(1/2), 57-67.

Bendick, M., Brown, L.E., \& Wall, K. (1999). No foot in the door: An experimental study of employment discrimination against older workers. Journal of Aging and Social Policy, 10(4), 5-23.

Biddle, J., Boden, L.I., and Reville, R. T. (2003). Older workers face more serious consequences from workplace injuries. Health and Income Security for an Aging Workforce Brief, 5, December. Washington, D.C.: National Academy of Social Insurance.

Bourgault, K., Lawrence, T., \& Steiniger, S. (2004). Aging and employment: Implications of an aging workforce in the development of human capital. In B. McIntosh (Ed.), Aging and the Workforce. Retrieved March 25, 2006 from http://www.bsad.uvm.edu/files/aging/chapter4.pdf.

Brooke, L. (2003). Human resource costs and benefits of maintaining a mature-age workforce. International Journal of Manpower, 24(3), 260-283.

Bruyère, S. (2000). Disability employment policies and practices in private and federal sector organizations. Ithaca, NY: Cornell University School of Industrial and Labor Relations Extension Division, Program on Employment and Disability.

Bruyère, S., Erickson, E., and VanLooy, S. (in press). Information technology (IT) accessibility: Implications for employment of people with disabilities. Work, 27(4).

Burkhauser, R.V., Butler, J.S. \& Weathers II, R.R., (2001), How policy variables influence the timing of social security disability insurance applications. (Policy Brief). Ithaca, NY: Rehabilitation Research and Training Center for Economic Research on Employment Policy for Persons with Disabilities. Retrieved March 30, 2006 from http://digitalcommons.ilr.cornell.edu/edicollect/89

Canadian Centre for Occupational Health and Safety (2002). OSH Answers: Aging Workers. Retrieved March 3, 2006 from http://www.ccohs.ca/oshanswers/psychosocial/aging_workers.htm 
Card, L., \& O’Donnell, M. (2004). Ejection vs. retention: Weighing the programs and cons of employing elders. In B. McIntosh (Ed.), Aging and the workforce. Retrieved March 24, 2006 from

http:/www.bsad.uvm.edu/Research/inProgress/Resources/AgingEmp/

Collison, J. (2005). 2005 future of the U.S. labor pool. Survey Report. Alexandria, VA: Society for Human Resource Management.

Collison, J. (2006). 2006 access to human capital and employment verification. Survey report. Alexandria, VA: Society for Human resource Management.

Czaja, S. J., \& Hiltz, S. R. (2005). Digital aids for an aging society. Communications of the ACM, 48(20), 43-44.

Delgoulet, C., \& Marquie, J.C. (2002). Age difference in learning maintenance skills: A field study. Experimental aging Research, 28(1), 25-37.

Dixon, C. G., Richard, M., \& Rollins, C. W. (2003). Contemporary issues facing aging Americans: Implications for rehabilitation and mental health counseling. Journal of Rehabilitation, 69 (2), 5-12.

Doyle, R.H., Dixon, C. G., \& Moore, C. L. (2003). Expanding rehabilitation services to meet the legal needs of aging Americans. Journal of Rehabilitation, 69(2), 49-54.

Finch, J., \& Robinson, M. (2003). Aging and late-onset disability: Addressing workplace accommodation. Journal of Rehabilitation, 69(2), 38-42.

Frank, F.D., \& Taylor, C.R. (2004). Talent management: Trends tat will shape the future. Human Resource Planning, 27(1), 33-41.

Ghosheh, N.S., Lee, S., \& McCann, D. (2006). Conditions of work and employment for older workers in industrialized countries: Understanding the issues. Geneva, Switzerland: International Labour Office.

Hansson, R.O., Robson, S.M., \& Limas, M.J. (2001). Stress and coping among older workers. Work, 17(3), 247-256.

He, W., Sengupta, M., Velkoff, V.A., \& DeBarros, K.A. (2005). U.S. Department of Census. Current population reports, P. 23-209, 65+ in the United States: 2005. Washington, D.C.: U.S. Government Printing Office.

Helman, R., Copeland, C., VanDerhei, J. (2006). Will more of us be working forever? The 2006 Retirement Confidence Survey. Issue Brief, No. 292. Employee Benefits Research Institute, April. 
Ho, P. (2002). Disability and employment status among older workers. Washington, D.C.: National Rehabilitation Hospital, Center for Health and Disability Research.

Hotchkiss, J. (2003). The labor market experience of workers with disabilities: The ADA and beyond. Kalamazoo, MI: Upjohn Institute for Employment Research.

Ilmarinen, J. (2002). Physical requirements associated with the work of aging workers in the European Union. Experimental Aging Research, 28(1), 7-23.

Institute of Management and Administration (2005). Aging workforce creates challenges \& opportunities, new data show. IOMA's Report on Compensation \& Benefits for Law Offices, 05(12), 7.

Johnson, R.W., \& Neumark, D. (1996). Age discrimination, job separations, and employment status of older workers: Evidence from self-reports. National Bureau of Economic Research (NBER) Working Paper Series, No. 5619. Cambridge, MA: NBER.

Kramer, N. (1995). Employee benefits for older workers. Monthly Labor Review, 118(4), 21-27.

Lahey, J.N. (2005). Do older workers face discrimination? Issue Brief, Center for Retirement Research, No. 33. Boston, MA: Boston College, Center for Retirement Research.

Larkin, V.M., Alston, R. J., Middleton, R. A., \& Wilson, K.B. (2003). Underrepresented ethnically and racially diverse aging populations with disabilities: Trends and recommendations. Journal of Rehabilitation, 69(2), 26-31.

Laws, J. (2006). Retirement: Don’t bet on it. Occupational Health \& Safety, 75(2), 4.

Minter, S. G. (2002, September). Ergonomic challenge: the aging work force. Occupational Hazards. September 2002, p. 6.

Mitchell, J.M., Adkins, R. H., \& Kempt, B.J. (2006). The effects of aging on employment of people with and without disabilities. Rehabilitation Counseling Bulletin, 49(3), 157-165.

Morton, L., Foster, L., and Sedlar, J. (2005). Managing the mature workforce. New York: NY: The Conference Board.

Platt, R.K. (2001). The aging work force: Angst for organizations, baby boomers. Workspan, 44(1), 26-29.

Reynolds, S., Ridley, N., \& Van Horn, C.E. (2005). A work-filled retirement: workers' changing views on employment and leisure. August. New Brunswick, NJ: Rutgers, the State University of New Jersey, John J. Heldrich Center for Workforce Development. 
Schultz, K.S., Sirotnik, B.W., \& Bockman, S. (2000). Plight of an aging workforce. Research Report funded by the California State University Faculty Research Fellows program for the California Assembly speaker's Office of Member Services. Retrieved March 24, 2006 from http://www.csus.edu/calst/Government_Affairs/reports/ffp36.pdf

Smith, S. (2004). Protecting vulnerable workers. Occupational Hazards, 66 (4), 25-28.

Stock, W.A., \& Beegle, K. (2004). Employment protections for older workers: Do disability discrimination Laws matter? Contemporary Economic Policy, 22(1), 111-126.

Swett, E. A., \& Bishop, M. (2003). Mental health and the aging population: Implications for rehabilitation counselors. Journal of Rehabilitation, 69(2), 13-18.

Tepas, D. I., \& Barnes-Farrell, J.L. (2002). Is worker age a simple demographic variable? Experimental Aging Research, 28, 1-5.

Turning boomers into boomerangs. (2006, February 18). The Economist, 8465, 75. Retrieved March 24, 2006 from ProQuest.

U.S. Census Bureau (2004). U. S. Census Bureau population projects. Retrieved March 17, 2005 from http://www.census.gov/ipc/www/usinterimproj/

Vargo, T.J., \& Grzanowicz, G. W. (2002). Strategies for effective disability management. Employee Benefit Plan Review, 57(6), 24-27.

Weathers II, R. R. (2006). Disability Prevalence Rates For an Aging Workforce. Ithaca, NY: Cornell University, Rehabilitation Research and Training Center on Employment Policy.

Williams, A. H. (2002). How to manage your aging workforce. Brentwood, TN: M. Lee Smith Publishers, LLC.

Yelin, E., Sonneborn, D., \& Trupin, L. The prevalence and impact of accommodations on the employment of persons 51-61 years of ago with musculoskeletal conditions. Arthritis Care and Research, 13(3), 168-176.

Zwerling, C., Whitten, P.S., Sprince, N.L., Davis., C., Wallace, R.B., Blanck, P., \& Herringa, S.G. (2003). Workplace accommodations for people with disabilities: National Health Interview Survey Disability Supplement, 1994-1995. Journal of Occupational and Environmental Medicine, 45(5), 517-525. 
DM and the Aging Workforce

\section{Percent Change Between 2000 and 2015 for 55-64 Age Group by Country}

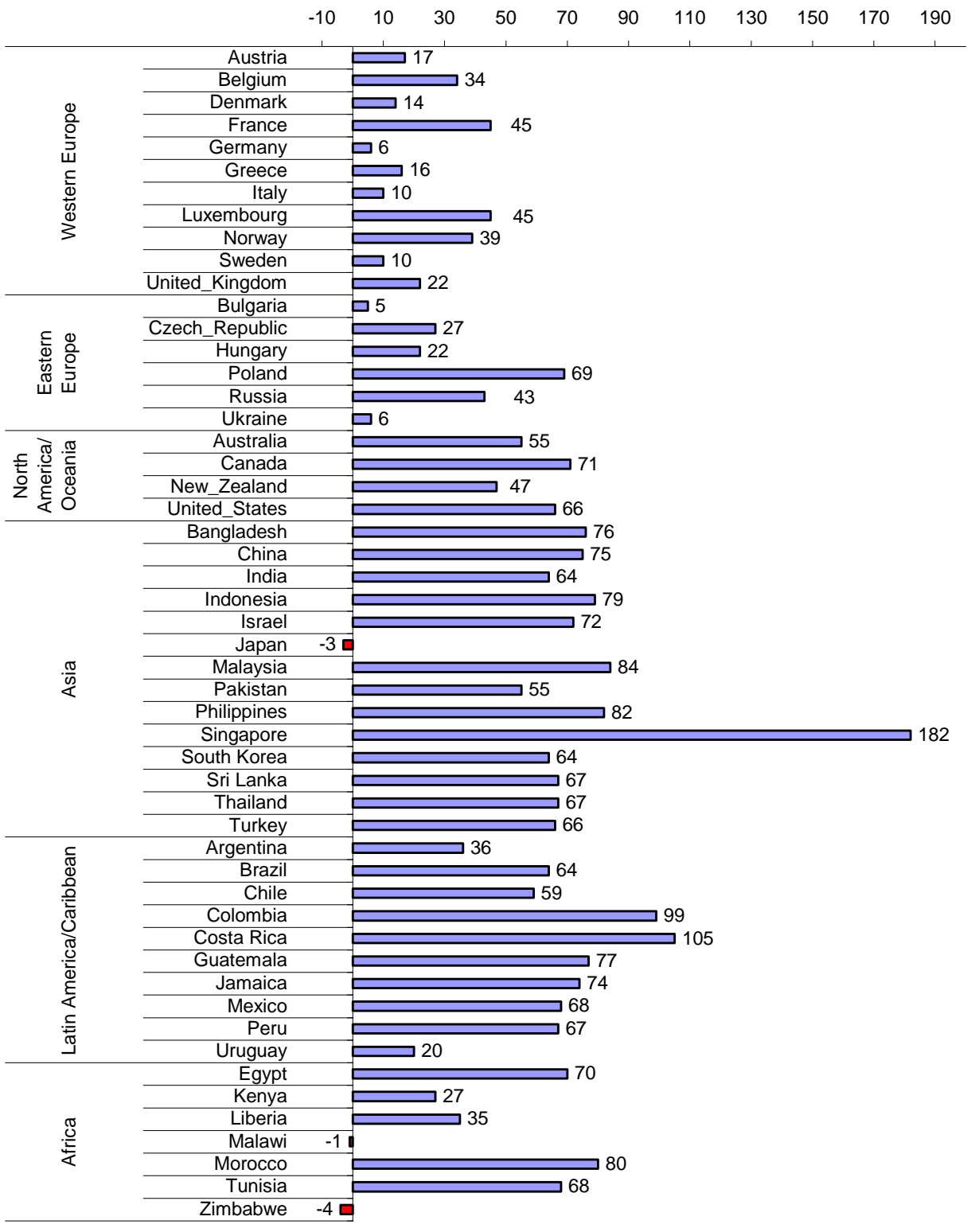

Source: Cornell Rehabilitation Researh and Training Center on Disability Statisitcs, using data from Kinsella, K., \& Velkoff, V. (2001). An Aging World: 2001 (U.S. Census Bureau, Series P95/01-1). Washington, DC: U.S. Government Printing Office. 